\title{
The role of brachytherapy for margin control in oral tongue squamous cell carcinoma
}

\author{
Ilia lanovski ${ }^{1}$, Alex M. Mlynarek2 ${ }^{2}$ Martin J. Black², Boris Bahoric ${ }^{3}$, Khalil Sultanem³ and Michael P. Hier ${ }^{2 *}$ (D)
}

\begin{abstract}
Background: The aim of this study is to assess the feasibility and effectiveness of using peri-operative brachytherapy (BRTx) for positive/narrow margins present post primary surgical resection of oral tongue squamous cell carcinoma (OTSCC).
\end{abstract}

Methods: Prospective single-centre study of patients with OTSCC (T1-3, NO-3, M0) treated with resection of primary tumour \pm regional nodal resection and intra-operative insertion of BRTx catheters. BRTx was administered twice daily at 40.8Gy/12Fr for 'Positive' ( $\leq 2 \mathrm{~mm}$ ) margins, at 34Gy/10Fr for 'Narrow' (2.1-5 mm) margins, and not given for 'Clear' (> $5 \mathrm{~mm}$ ) margins over the course of 5-6 days, 3-5 days post operatively.

Results: Out of 55 patients recruited 41 patients (74.6\%) were treated with BRTX, as 12 patients had clear margins and 2 patients had unfavourable tumour anatomy for catheter insertion. EBRTx was avoided in 64.3\% of patients. Overall Survival (OS) at 3 and 5 years was 75.6 and 59.1\% respectively, while Disease Specific Survival (DSS) was 82.3 and $68.6 \%$ at 3 and 5 years respectively. Recurrence and survival outcomes were not associated with margin status or the use of or specific dose of BRTx on Cox regression analysis. Acute and late toxicity secondary to BRTx was minimal.

Conclusions: The use of BRTX after primary OTSCC resection with positive/narrow margins \pm EBRTx to the neck \pm CTx achieves outcomes comparable to traditional treatment of surgery followed by re-resection or EBRTX \pm CTx. Morbidity associated with oral cavity EBRTx or secondary resection and reconstruction is thus avoided. Both acute and late toxicity rates are low and compare favourably with other BRTX OTSCC studies.

Trial registration: Retrospectively registered. https://www.mcgill.ca/rcr-rcn/files/rcr-rcn/2017.06.05_rcn_hn.pdf. Level of evidence: 4

Keywords: Oral cavity, Radiation therapy, Neck dissection, Squamous cell carcinoma, Tongue cancer, Oral cancer, Brachytherapy, Survival

\footnotetext{
* Correspondence: mhier@jgh.mcgill.ca

Presented as a poster at Combined Otolaryngology Spring Meeting, American Head \& Neck Society Meeting, National Harbor, April 18-19, 2018

${ }^{2}$ Department of Otolaryngology - Head \& Neck Surgery, Jewish General Hospital, McGill University, Montreal, Quebec, Canada

Full list of author information is available at the end of the article
}

(C) The Author(s). 2020 Open Access This article is licensed under a Creative Commons Attribution 4.0 International License, which permits use, sharing, adaptation, distribution and reproduction in any medium or format, as long as you give appropriate credit to the original author(s) and the source, provide a link to the Creative Commons licence, and indicate if changes were made. The images or other third party material in this article are included in the article's Creative Commons. licence, unless indicated otherwise in a credit line to the material. If material is not included in the article's Creative Commons licence and your intended use is not permitted by statutory regulation or exceeds the permitted use, you will need to obtain permission directly from the copyright holder. To view a copy of this licence, visit http://creativecommons.org/licenses/by/4.0/ The Creative Commons Public Domain Dedication waiver (http://creativecommons.org/publicdomain/zero/1.0/) applies to the data made available in this article, unless otherwise stated in a credit line to the data. 


\section{Background}

Oral tongue squamous cell carcinoma (OTSCC) represents approximately $40 \%$ of all oral cavity squamous cell carcinoma (OCSCC) [1] and its incidence is increasing internationally $[2,3]$. OTSCC is conventionally treated with surgery: wide local excision (WLE) of the primary tumour, elective neck dissection guided by depth of invasion and size of the primary in clinically negative neck (cN0), and therapeutic neck dissection for clinically evident regional metastasis. Adjuvant external beam radiation therapy $(\mathrm{EBRTx}) \pm$ Chemotherapy $(\mathrm{CTx})$ is given for high risk features: presence of multiple positive regional nodes, extra nodal extension (ENE), Lympho-vascular spread (LVS), peri-neural invasion, and positive/narrow resection margins $(<5 \mathrm{~mm})$.

Adequate resection margins $(\geq 5 \mathrm{~mm})$ remain at the forefront of the ablative surgeon's aims, as positive/narrow margins are associated with increased risk of local recurrence in Head and Neck cancer [4] and affect survival in OTSCC specifically [5]. Inadequate margins are found in 10-16\% of all head and neck cancer cases, despite best surgical attempts [6] and the overall salvage cure rate of recurrent OCSCC has been documented between $21 \%$ [7] - 35\% [8].

The management of positive/narrow margins poses a challenge to the multi-disciplinary team (MDT). Revision surgery is frequently made difficult due to the use of a free flap or a local flap for the reconstruction of the primary tongue defect, and adjuvant EBRTx is thus recommended. EBRTx for close/positive margins in OTSCC has been shown to improve survival but not to the level of clear margins [5]. EBRTx applied to the oral cavity is associated with significant morbidity, such as mucositis, xerostomia, dysphagia, and osteoradionecrosis (ORN) of the mandible.

Brachytherapy (BRTx) allows for the delivery of high dose conformal radiation to the target site in a shorter time frame, while sparing surrounding normal structures. It has been used as the primary and adjuvant treatment of OTSCC in France, Japan, Czech Republic, South Africa, and Spain [9-14] but there has been no reported North American experience.

The aim of this study was to evaluate the feasibility, local and loco-regional control, survival outcomes, and complications of peri-operative BRTx treatment for positive/narrow margins present post primary surgical resection of OTSCC \pm EBRTx to the neck \pm CTx depending on pathological indicators.

\section{Methods}

This single-centre prospective project was approved by the Research Ethics Committee of Jewish General Hospital, McGill University. Patients diagnosed with T1-3, N0-3, M0 OTSCC were identified at the multidisciplinary tumour board (MTB) and it was established that the primary tumour was amenable to WLE limited to a partial glossectomy and insertion of BRTx catheters \pm surgical resection of ipsilateral/bilateral regional cervical lymph nodes on elective/therapeutic basis. Each patient underwent a thorough clinical examination by at least two members of the surgical team and a single invariable radiation oncologist to assess for the possibility of BRTx. BRTx was not considered feasible in cases where OTSCC came to involve the mandible directly, or was approaching the mandible via floor of mouth (FoM) so as to require BRTx catheters to be placed in direct contact with the bone. The following exclusion criteria were applied: Zubrod performance status $>2$, prior EBRTx to the head and neck region, previous CTx, prophylactic use of amifostine or pilocarpine, previous other malignancy except nonmelanomatous skin cancer or a carcinoma not of head and neck origin $\leq 5$ years, other treatment for head and neck cancer, active untreated infection. Patients fitting the above criteria were offered to take part in the study and study-specific informed consent form was signed prior to registration.

All patients underwent a partial glossectomy \pm appropriate neck dissection (ND) by the surgical ablative team. Prior to reconstruction of the oral tongue defect the surgical reconstructive team and a radiation oncologist assessed the tongue defect and intra-operatively placed afterloading-BRTx Comfort-Catheters (Elekta, Stockholm, Sweden) through hollow stainless-steel catheter guides. Free-hand technique application was used and the catheters were placed parallel to the resection margin, 3-5 mm from the margin itself. The catheters were positioned in a single plane $1-1.5 \mathrm{~cm}$ apart and parallel to each other. These were secured in place with a semi-lunar button in contact with the patient's skin, without the need to suture the catheters in place. The tongue defect was subsequently reconstructed with a local/free flap (Fig. 1). All patients received a tracheostomy.

Following surgery, surgical histopathology was rushed through so as to either remove the BRTx catheters or begin adjuvant BRTx to the tongue within 3-5 days post-operatively. BRTx in the form of high dose rate Iridium $^{192}$ was administered twice daily depending on histopathological findings as follows: 'Clear' margins (> $5 \mathrm{~mm}$ ) no BRTx with catheter removal on the ward; 'Narrow' margins (2.1-5 mm) received 34Gy/10Fr; 'Positive' margins $(\leq 2 \mathrm{~mm})$ received $40.8 \mathrm{~Gy} / 12 \mathrm{Fr}$. BRTx was administered twice daily 6 or more hours apart and over the course of 5-6 days.

Target volumes were defined on a planning CT-scan in 'in treatment' position, Clinical Target Volume (CTV) was defined as an expansion of $5 \mathrm{~mm}$ around the radioopaque catheters. The mandible as an Organ at Risk (OAR) was contoured in all cases, no Planning Target Volume (PTV) added. Inverse planning was done using 

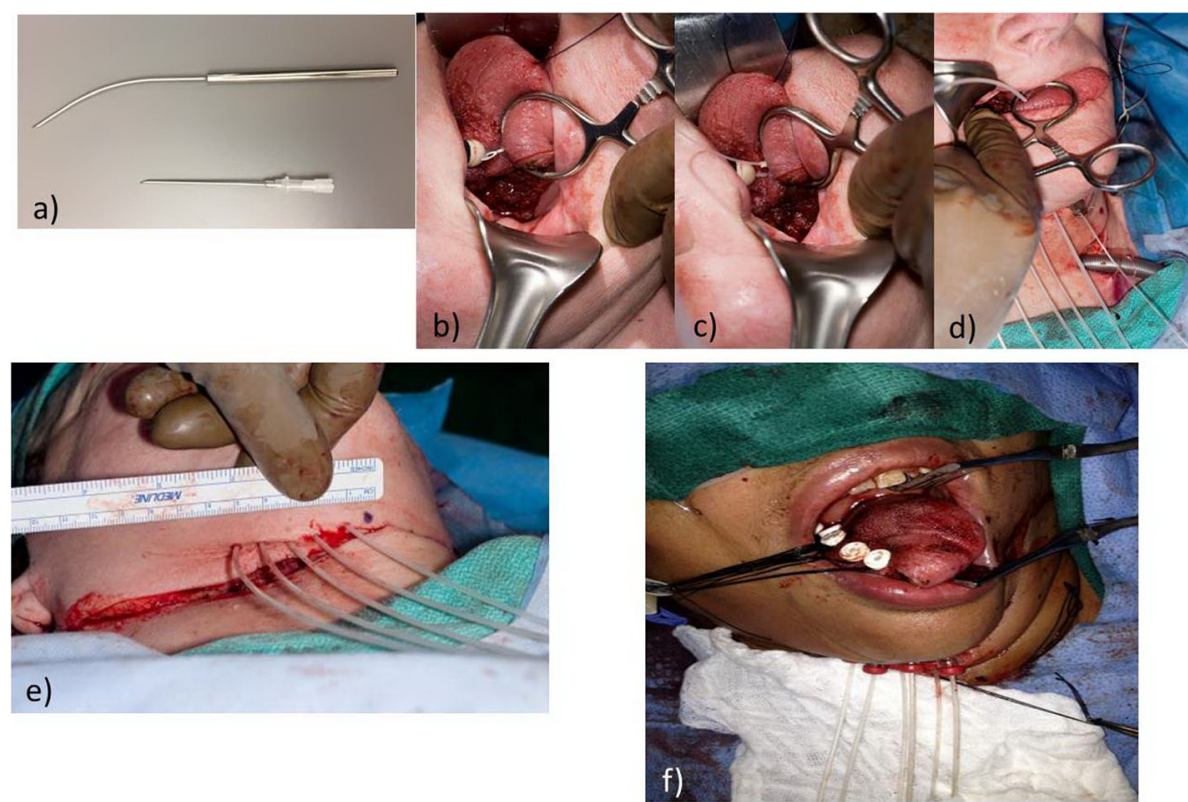

Fig. 1 Brachytherapy catheter insertion technique. a Stainless steel Brachytherapy catheter insertion guide or 14 Gauge Intra-venous catheter. b Catheter guide inserted into residual tongue tissue 3-5 $\mathrm{mm}$ from the resection margin. c Brachytherapy after-loading catheter passed through the insertion guide. $\mathbf{d}$ Catheter is passed through the skin and catheter guide removed. e Catheters are placed $1-1.5 \mathrm{~cm}$ apart and parallel to each other. $\mathbf{f}$ catheters are secured to skin with semi-lunar buttons. Silk ties placed around the catheters intra-orally and left long for ease of subsequent removal. Note - reconstructive flap is inset after the catheters are secured in place in a standard manner

the Oncentra ${ }^{\circ}$ Brachytherapy planning system (Elekta) with the following constraints to be respected: at least $98 \%$ of the prescribed dose covering the target, the volume receiving $150 \%$ to be less than $40 \%$, and the point dose on the mandible not to exceed $100 \%$ of the prescribed dose. The treatment was delivered on the MicroSelectron ${ }^{\circ}$ HDR afterloading platform (Elekta). Adequate position of the catheters was confirmed clinically at each treatment with $\mathrm{CT}$ planning repeated if there was any change in position secondary to contour changes related to swelling or surgical changes.

External beam radiation to the neck was given to patients with intermediate to high risk criteria on pathology including $>2$ positive regional nodes, ENE, and bilateral neck involvement.

For the neck radiation, the neck position at the time of the brachytherapy was reproduced and patient immobilized with thermoplastic mask and custom head rest. The neck was treated with Intensity Modulated Radiotherapy (IMRT) using fixed beam IMRT initially then Volumetric Modulated Arc Therapy for more recent cases (RapidArc, Varian Medical Systems, Palo Alto, California, USA). Target volume and OARs were contoured as per international guidelines [15].

The involved neck was treated to a dose of $55 \mathrm{~Gy} / 25 \mathrm{Fx}$, the non-involved neck limited to $50 \mathrm{~Gy} / 25 \mathrm{Fx}$. In order to account for overlap with the brachytherapy treatment, the BRTx planning CT scan was fused with the EBRTx planning CT scan and the $50 \%$ isodose line delivered by brachytherapy was contoured as an OAR and every attempt was taken to limit the dose to this area to $25 \mathrm{~Gy}$ maximum dose.

Chemotherapy in the form of Carboplatin $100 \mathrm{mg} / \mathrm{m}^{2}$ and Taxol $40 \mathrm{mg} / \mathrm{m}^{2}$ given weekly concomitant to radiation was used if there is pathological evidence for extranodal extension (ENE).

As per institutional policy, all patients are followed up in the multidisciplinary head and neck clinic for at least 5 years post treatment completion, with annual chest imaging (chest $\mathrm{x}$-ray or $\mathrm{CT}$ ) as well as thyroid function tests in patients treated with EBRTx to their neck. Presence, site, and date of recurrence were recorded, as were any treatment related complications using the Radiation Therapy Oncology Group (RTOG) acute/late radiation morbidity scoring schema.

" $R$ " statistical software was used to analyse the gathered data. The Kaplan-Meier method was used to calculate survival and control outcomes, while the Cox regression model was used to assess the influence of various factors in a univariate and multi-variate analysis.

\section{Results}

Between September 2009 and April 201755 patients with biopsy proven OTSCC (T1-3, N0-2, M0), median age of 62 (24-92), were recruited into the study and underwent a partial glossectomy \pm appropriate ND. 
Patient and tumour details are provided in Table 1. Fifty three patients had BRTx catheters inserted intra-operatively. Two patients did not undergo BRTx catheter insertion due to their potential proximity to the mandible and hyoid bone, thus increasing the risk of ORN. Of note, these 2 patients had clear margins on subsequent pathological analysis and would have had no BRTx administered according to the study protocol, thus not skewing primary study outcomes.

In total 54 patients were treated with unilateral or bilateral ND (as per primary tumour indications), with one patient avoiding ND for a T1 with less than $3 \mathrm{~mm}$ depth of invasion. One patient underwent a delayed/staged ND following primary tumour pathological analysis.

Analysis of primary tumour resection is shown in Table 2. Only 16 patients (29.1\%) required and received EBRTx to the neck for ENE/> 2 positive nodes, one of which had 'clear' primary resection margins. Thus, 27 patients out of 43 (64.3\%) were spared EBRTx all together due to the use of BRTx, and 42 patients were spared EBRTx to the oral cavity or further surgical resection that may otherwise be recommended for 'narrow' or 'positive' margins. Treatment type administered by overall tumour stage is provided in Table 3.

A total of 12 patients $(21.8 \%)$ recurred over the median follow up time of 25.4 months (2.9-81.3), with the median time to recurrence being 11 months (6.838.8). Further details of observed recurrences are provided in Table 4.

Table 1 Patient Demographics

\begin{tabular}{lll}
\hline & Number & $\%$ \\
\hline Male & 26 & 47.3 \\
Female & 29 & 52.7 \\
pT stage & & \\
1 & 27 & 49.1 \\
2 & 26 & 47.3 \\
3 & 2 & 3.6 \\
4 & 0 & 0 \\
pN stage & & \\
0 & 36 & 65.4 \\
1 & 8 & 14.6 \\
2 & 11 & 20.0 \\
AS/PG & & \\
I & 22 & 40.0 \\
II & 14 & 25.4 \\
III & 8 & 14.6 \\
IV & 11 & 20.0 \\
Tumour Differentiation & & \\
Well & 27 & 49.1 \\
Moderately & 21 & 38.2 \\
Poor & 7 & 12.7 \\
\hline
\end{tabular}

AS/PG Anatomic Stage/Prognostic Groups
The Kaplan-Meier model revealed an overall survival (OS) of 75.6 and $59.1 \%$ at 3 and 5 years respectively while Disease Specific Survival (DSS) was $82.3 \%$ at 3 years and $68.6 \%$ at 5 years Fig. 2. Disease Free Survival (DFS), Local Control (LC), and Loco-regional Control (LRC) at 3 years were 74.3, 86.3, and 77.7\% respectively Fig. 3.

Cox regression analysis failed to show an effect from age, ENE, use of and dose of BRTx, and tumour grade on OS, DSS, LC, LRC. Importantly, margin status was not seen to have an effect on the above various outcomes, likely secondary to the use of BRTx. Multivariate analysis showed a Hazard Ratio (HR) of 4.04 (1.12-14.53) for a primary tumour $\geq \mathrm{pT} 2$, nodal disease of $\mathrm{pN} 2$ having an HR of 5.25, stage IV disease having a HR of 10.53, Chemoradiation having an HR of 3.54, on Overall Survival. Univariate analysis showed a significant association between pT3 tumour and worse OS (HR 38.05), DSS (HR 31.65), LC (HR 16.68), and LRC (HR 17.72); while pN2 nodal disease was associated with worse OS (HR 5.25) and DSS (HR 4.63). Overall these associations between a more advanced tumour stage and survival and control outcomes have been previously reported and were expected.

There was minimal acute toxicity during the BRTx \pm EBRTx. Mild and transient tongue swelling was noted in all patients during BRTx, with the airway being secured with the intra-operative tracheostomy. In 7 patients (12.7\%) treated with both EBRTx and CTx grade 3 transient radiation dermatitis was noted. There was a single episode of haemorrhage during the removal of BRTx catheters on the ward at the beginning of the trial, requiring an examination and cautery under general anaesthesia (grade 4).

Late toxicity was noted in 3 patients, characterized by persistent pain localizing to the oral tongue and requiring intermittent opioid-based analgesia (grade 2). Of note, no ORN, dysphagia, or xerostomia requiring salivary substitution was identified over the course of the follow up period.

\section{Discussion}

This study demonstrates the feasibility of using BRTx for margin control in OTSCC. Out of the 55 enrolled patients 53 had the BRTx catheters inserted without difficulty and patients tolerated the catheters well post operatively. The rapid pathological analysis of the resected primary specimen ensured that a decision to administer BRTx and the dose applied could be determined in a timely manner, and treatment was completed within $8-12$ days post-surgery. Overall, $25.4 \%$ of patients had catheters removed without the need for BRTx administration due to 'clear' (>5 mm) surgical margins. Patient recovery post BRTx catheter removal, whether BRTx administered or not, matched that of patients recovering from partial glossectomy with local/ free flap reconstruction in time and complications. 
Table 2 Treatment Details

\begin{tabular}{|c|c|c|c|c|c|c|}
\hline \multicolumn{7}{|c|}{ Table 2 - Treatment Details } \\
\hline & & Number & $\%$ & & Number & $\%$ \\
\hline \multirow[t]{3}{*}{ Margins } & $\begin{array}{l}\text { 'Clear' } \\
>5 \mathrm{~mm}\end{array}$ & 13 & 23.6 & & & \\
\hline & $\begin{array}{l}\text { 'Narrow' } \\
2.1-5 \mathrm{~mm}\end{array}$ & 25 & 45.5 & & & \\
\hline & $\begin{array}{l}\text { 'Positive' } \\
\leq 2 \mathrm{~mm}\end{array}$ & 17 & 30.9 & & & \\
\hline \multirow[t]{2}{*}{ Brachytherapy } & $\begin{array}{l}\text { Not } \\
\text { Treated }\end{array}$ & $14+$ & 25.4 & & & \\
\hline & Treated & 41 & 74.6 & & & \\
\hline \multicolumn{4}{|c|}{\begin{tabular}{l|l} 
& \\
\cline { 2 - 2 }
\end{tabular}} & Minimal Dose 34Gy/10Fr & 26 & 47.3 \\
\hline & & & & Maximal Dose $40.8 \mathrm{~Gy} / 12 \mathrm{Fr}$ & 15 & 27.3 \\
\hline \multirow{2}{*}{$\begin{array}{l}\text { EBRTx to Neck } \\
\text { alone }\end{array}$} & Given & 16 & 29.1 & & & \\
\hline & Not given & 39 & 70.9 & & & \\
\hline \multirow{2}{*}{$\begin{array}{l}\text { Adjuvant CTx + } \\
\text { EBRTx to neck }\end{array}$} & Given & 7 & 12.7 & & & \\
\hline & Not given & 48 & 87.3 & & & \\
\hline \multicolumn{7}{|c|}{$\begin{array}{l}\text { + No Brachytherapy given: } 13 \text { patients had clear margins, } 1 \text { patient had narrow margins but refused } \\
\text { to have BRTx post catheter insertion }\end{array}$} \\
\hline \multicolumn{7}{|c|}{ EBRTx - External Beam Radiotherapy; CTx - Chemotherapy; Gy - Grey; Fr - Fractions } \\
\hline
\end{tabular}

† No Brachytherapy given: 13 patients had clear margins, 1 patient had narrow margins but refused to have BRTx post catheter insertion EBRTx External Beam Radiotherapy, CTx Chemotherapy, Gy Grey, Fr Fractions

Although all patients with BRTx catheters required a tracheostomy for safe airway management, considering that a large proportion of OTSCC require a flap for reconstruction with a tracheostomy, this did not add considerable morbidity to the patient population. All patients were successfully de-cannulated 1-2 days after catheter removal.

This study's primary outcomes compare favourably with previously published reports on the use of BRTx for margin control in OTSCC +/- EBRTx +/- CTx, as well primary BRTx treatment and 'traditional' treatment with surgery followed by EBRTx +/- CTx (Table 5).

Overall only 8 patients $(14.5 \%)$ in this study showed evidence of acute complications: 7 patients $(12.7 \%)$ that were treated with combination of EBRTx + CTx developed transient RTOG Grade 3 radiation dermatitis and 1 patient experienced an episode of haemorrhage from the tongue when BRTx catheters were removed on the ward. Of note, the haemorrhage occurred during the early phase of the trial and was likely related to catheter

Table 3 Treatment by Stage

\begin{tabular}{|c|c|c|c|c|}
\hline & \multicolumn{4}{|c|}{ Treatment Type } \\
\hline & Surgery alone & Surgery + BRTx & Surgery + BRTx + CRTx & Surgery + CRTx \\
\hline \multicolumn{5}{|c|}{ AS/PG Stage } \\
\hline 1 & 8 & 14 & & \\
\hline II & 3 & 10 & & 1 \\
\hline III & 1 & 2 & 5 & \\
\hline IV & & 1 & 9 & 1 \\
\hline Total & 12 & 27 & 14 & 2 \\
\hline
\end{tabular}


Table 4 Recurrence

\begin{tabular}{|c|c|c|c|c|c|c|c|}
\hline \multicolumn{8}{|c|}{ Median time to Recurrence - 11 months $(6.8-38.8)$} \\
\hline & \multirow[b]{2}{*}{ Number } & \multirow[b]{2}{*}{$\%$ of all recurrences $(N=12)$} & \multirow[b]{2}{*}{$\%$ of all Patients $(N=55)$} & \multicolumn{4}{|c|}{ By AS/PG Stage } \\
\hline & & & & 1 & II & III & IV \\
\hline Total & 12 & 100 & 21.8 & 2 & 3 & 3 & 4 \\
\hline Local & 6 & 50.0 & 10.9 & 2 & 1 & 1 & 2 \\
\hline Isolated Regional & 4 & 33.3 & 7.3 & 0 & 2 & 2 & 0 \\
\hline Combined Loco-regional & 10 & 83.3 & 18.2 & 2 & 3 & 3 & 2 \\
\hline Isolated Distant & 2 & 16.7 & 3.6 & 0 & 0 & 0 & 2 \\
\hline Overall Distant & 4 & 33.3 & 7.3 & 0 & 0 & 0 & 4 \\
\hline
\end{tabular}

AS/PG Anatomic Stage/Prognostic Groups

removal technique, as there were no further complications of this nature with later cases. The bleeding episode was easily managed with cautery that was performed in the operating room under a general anaesthetic. Late complications were only observed in 3 patients (5.4\%) and were all limited to ongoing tongue pain requiring opioid medications (RTOG Grade 2). Of note, all 3 patients were treated with surgery and BRTx only, without further adjuvant EBRTx/CTx; two had the maximal dose $(40.8 \mathrm{~Gy} / 12 \mathrm{Fr})$ while one had the lower dose (34Gy/10Fr). It is thus not possible to discern whether it was the initial surgery or the subsequent BRTx that had the greatest contribution to the ongoing opioid analgesia requirements. The study showed no episodes of ORN, dysphagia, or xerostomia requiring salivary substitution. On the whole, the complications profile compares positively with published literature (Table 5).
Statistical analysis of the current findings demonstrates no difference in major outcomes between patients with negative $(>5 \mathrm{~mm})$ margins and positive/narrow $(\leq 5 \mathrm{~mm})$ margins treated with subsequent BRTx. This important finding suggests that BRTx may achieve a 'sterilization' effect on the margins, achieving a state where margins have no or limited impact on survival and control outcomes. This is further highlighted by the absence of differences in outcomes between the narrow $(2.1-5 \mathrm{~mm})$ and positive $(\leq 2 \mathrm{~mm})$ margins groups. Further consideration needs to be given to these findings in light of the recent paper published by Zanoni et al. in 2017 [26], which proposed margins $>2.2 \mathrm{~mm}$ in OTSCC to be considered 'clear' after the analysis of 381 cases. Combining the findings of both studies, it is possible to consider future use of high dose BRTx (40.8 Gy/ 12Fr) in patients

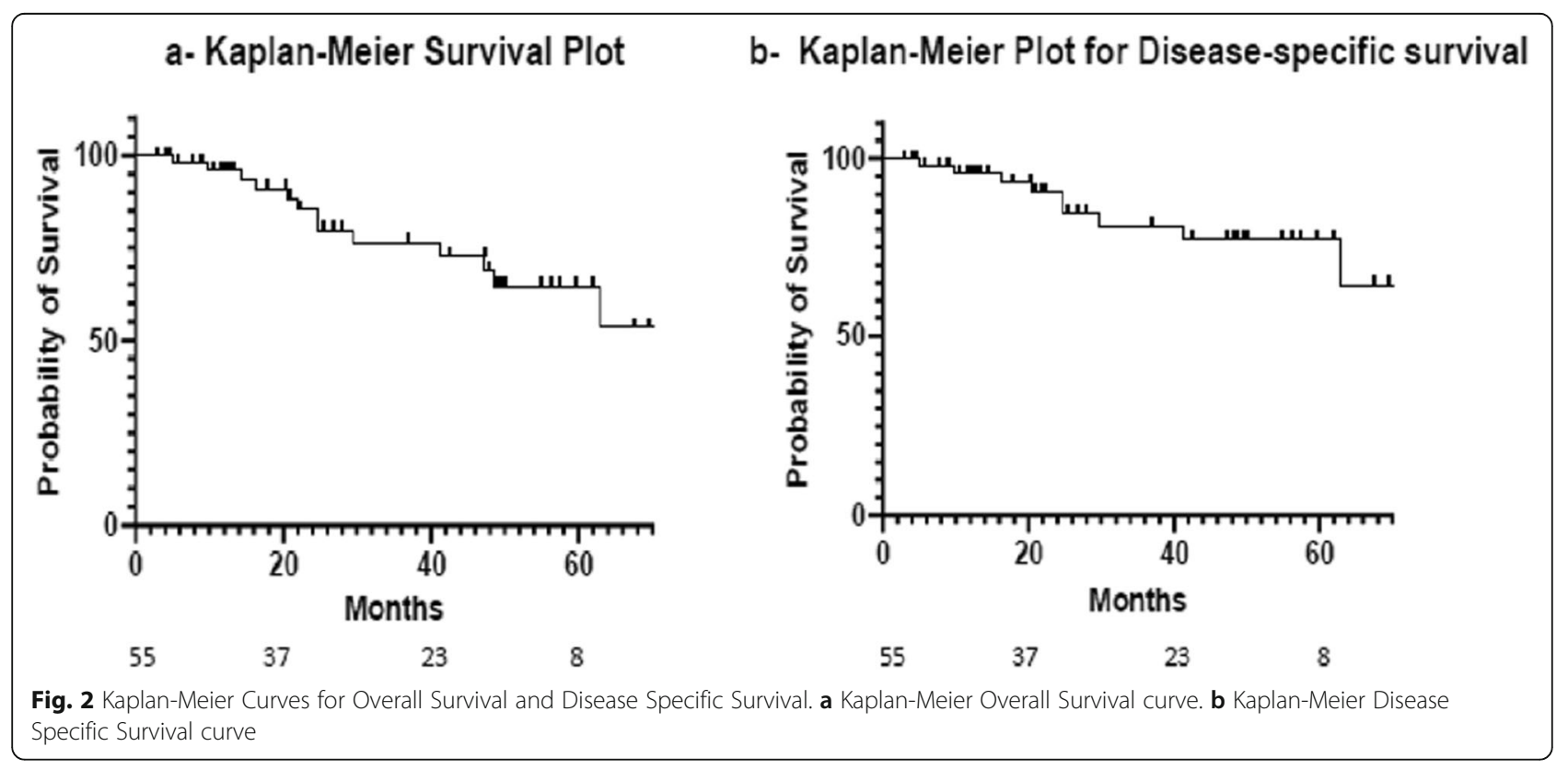



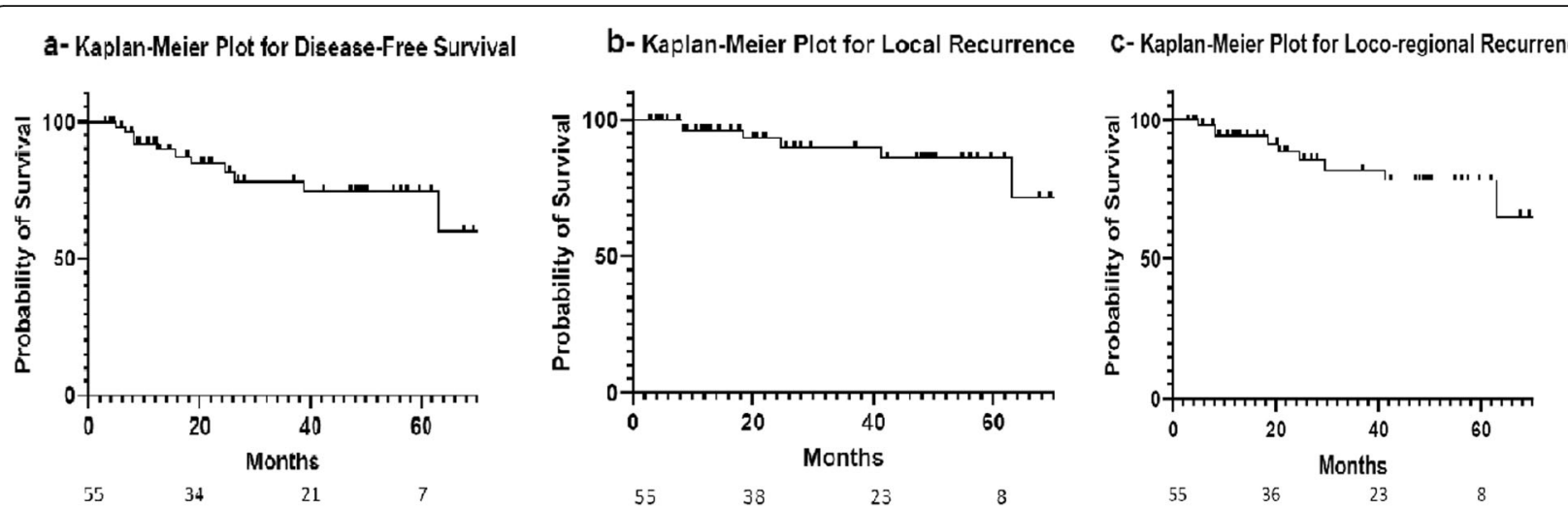

Fig. 3 Kaplan-Meier Curves for Disease-Free Survival, Local Recurrence, and Loco-Regional Recurrence. a Kaplan-Meier Disease Free Survival curve. b Kaplan-Meier Local Recurrence curve. c Kaplan-Meier Loco-Regional Recurrence curve

with $\leq 2.2 \mathrm{~mm}$ margins, sparing BRTx use in surgical margins that are greater.

The use of BRTx for margin control over 'traditional' revision surgery +/- EBRTx or EBRTx without further resection has both clinical and logistical advantages. Revision surgery is often made challenging secondary to the local/free flap reconstruction of the tongue and the need for timely operating list planning, potentially placing extra organizational/financial pressures on the surgical unit. Especially if EBRTx is subsequently required, second surgery can also impact the timing of when this can be delivered. Thus, the timing of treatment package may be extended beyond 11 weeks, which has been shown to be associated with worse OS and recurrence free survival in OCSCC [27]. Of note, in the current study $70.9 \%$ of patients had their treatment completed within 2 weeks (no EBRTx required), while the use of BRTx did not lead to any instances of EBRTx delay.

Although surgical margins are an important prognostic factor in OTSCC, these undergo an element of shrinkage by as much as $23.5 \%$ within 30 min of resection [28] with limited further shrinkage post formalin fixation [29]. Another contributing factor to margin shrinkage may be the use of monopolar cautery device for the resection of the primary tumour, secondary to thermal injury. During the initial phase of this study needle-point monopolar cautery was used for resection of the primary with $1.5 \mathrm{~cm}$ margins marked out after an intra-operative clinical assessment. A high rate of 'positive' and 'narrow' margins were noted between 2009 and 2011 (89\%) and 2012-2014 (94\%). As such, in 2015 the resection technique was changed to a cold steel (scalpel blade) excision, after $1.5 \mathrm{~cm}$ margins were clinically marked out on the tongue and local anaesthetic (LA) in the form of $1 \%$ Xylocaine with Adrenaline was infiltrated. Minimal localized bipolar diathermy was subsequently applied for haemostasis. This technique achieved a significant reduction in 'positive' and 'narrow' margins to $52 \%$ (Fig. 4), as well as proved to be a safe alternative to the classical use of monopolar diathermy with minimal blood loss. The use of cold steel excision with LA is the current practice for glossectomy cases at this institution.

The current study has a number of limitations that benefit from discussion. The absence of a control group in which patients would have undergone traditional' treatment in the form of surgery followed by re-resection or EBRTx for margin control +/- EBRTx $+/-$ CTx as required is noted. However, it is possible to compare the current outcome measures to the numerous papers published on the success rates of such treatment approach. As such, the treatment algorithm described in this study shows outcomes that are at least as good as the 'traditional' treatment approach to OTSCC management as well as the use of primary BRTx, with a significant reduction in both short-term and long-term side effects. The number of patients in the current study is limited to 55 , which although is smaller in comparison to most studies published on 'traditional' management of OTSCC, compares well to research published on the use of primary as well as adjuvant BRTx in OTSCC and shows clear outcomes that compare favourably to these. It is noted that $96.4 \%$ of this study's population represented T1-2 disease and thus these findings need to be applied with caution to T3 tumours.

It is of note that a more meaningful comparison of outcome should be done with a cohort limited to early $\mathrm{T}$ stage since our population is mostly composed of T12 cancers. Most of the studies in the literature analyze their outcome by global stage.

However, we did identify two studies by Ling et al. and Mroueh et al. [21, 23] that provide outcome for early $\mathrm{T}$ stage oral tongue cancer treated with adjuvant external beam radiation with or without concomitant chemotherapy. These two studies could be used as a comparison group to our cohort. 


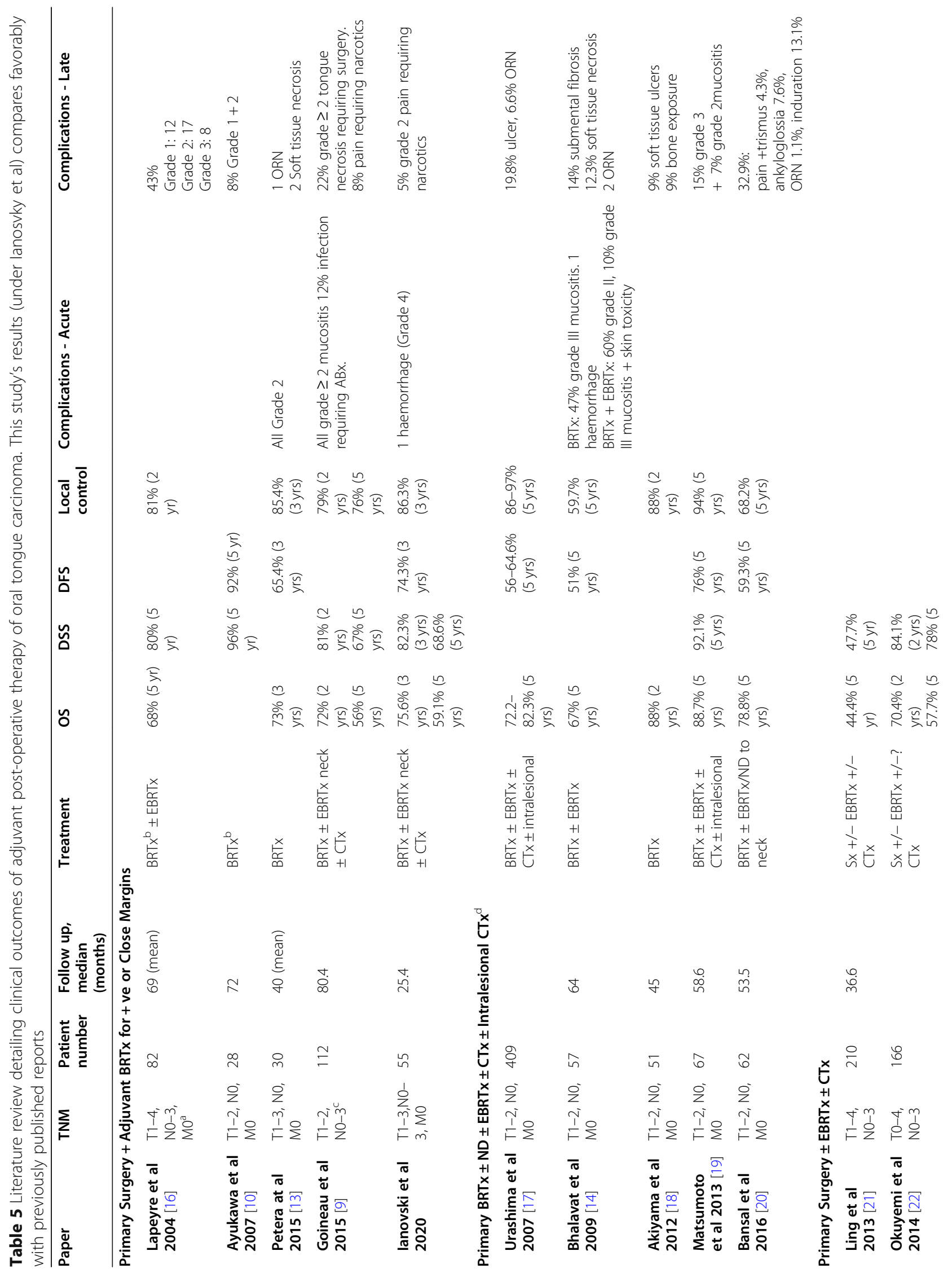




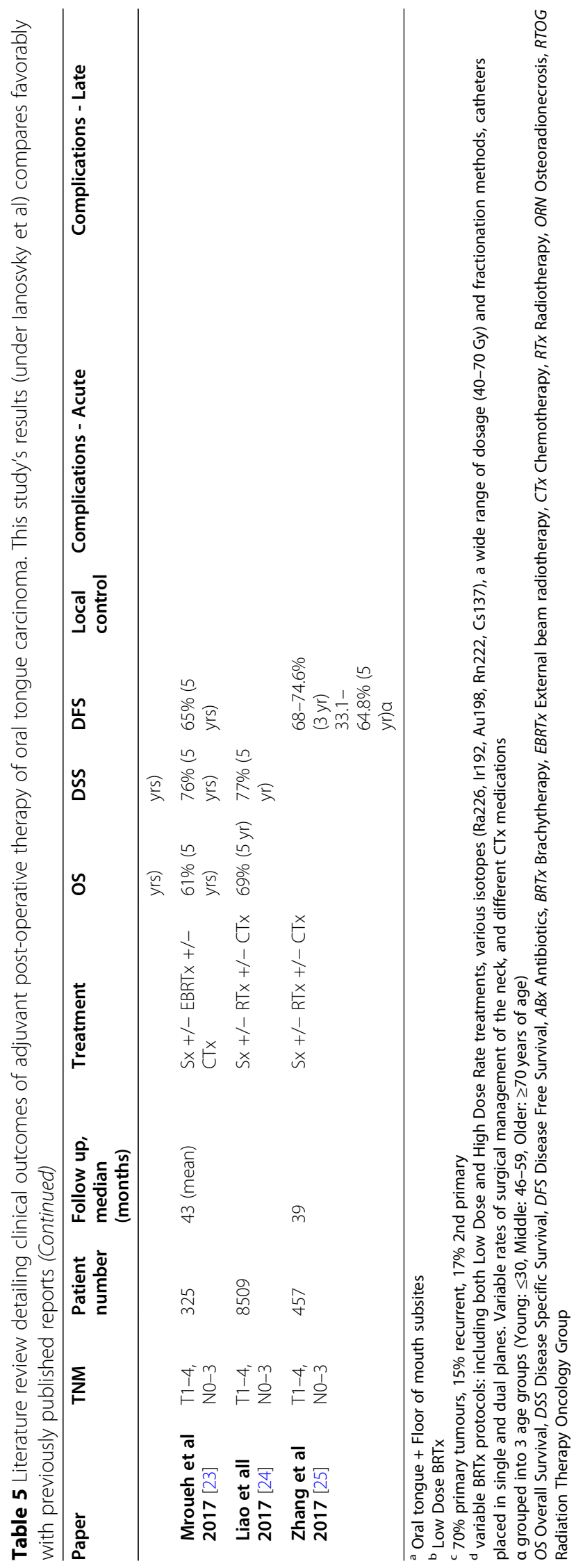




\section{Margin Status Over Time}

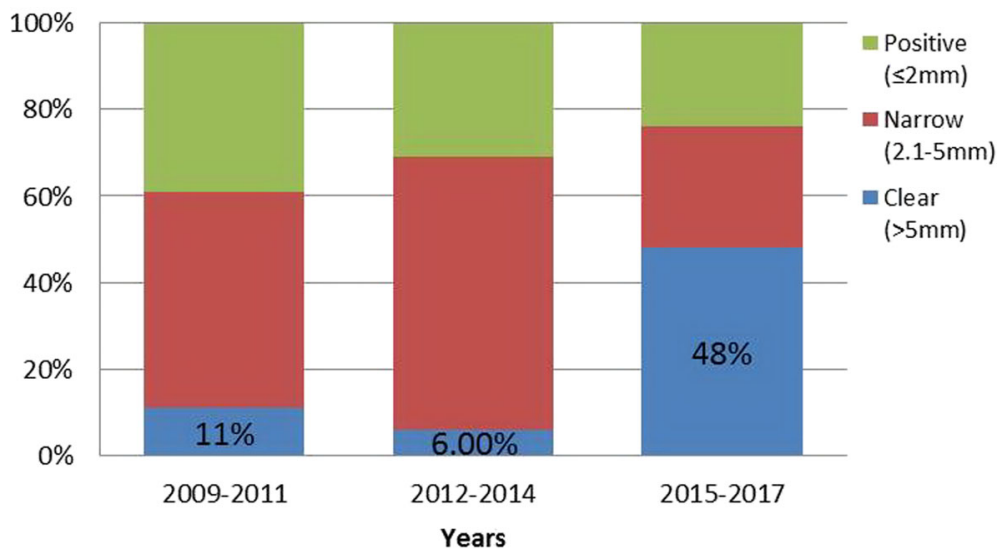

Fig. 4 Change in Margin status rates over time

Ling et al. reported a 3 year disease specific survival of 76.1 and $64.9 \%$ in 51 and 75 patients with stage T1 and $\mathrm{T} 2$ oral tongue carcinoma respectively. Mroueh et al. analyzed disease recurrence in 176 patients with stage T12 oral tongue cancer treated with modern techniques from 2005 to 2009 in Finland. They report a disease recurrence rate of 25 and $29 \%$ in stage $\mathrm{T} 1$ and $\mathrm{T} 2$ oral tongue cancer respectively.

Our results with a 3 year DSS of $82.3 \%$ and 3 year LRC of $77.7 \%$ compare favorably with this select population of early $\mathrm{T}$ stage oral tongue carcinoma.

Similarly, it is important to highlight the exclusion of T4 tumours in the current study (due to the concern for an elevated ORN risk) when comparing primary outcomes with 'traditional' treatment research in which these were included. Further work is planned to include higher T-stage tumours in BRTx research, although it is considered that some proportion of T3 tumours and the majority of T4 tumours would not be amenable to BRTx catheter insertion due to proximity of bone and elevated ORN risk. Although the incidence of short-term and long-term side effects was documented, quality of life (QoL) as a whole was not assessed in this patient population. Further investigation into patient-reported QoL measures with BRTx use in OTSCC management will be of important benefit.

\section{Conclusions}

The results of our prospective study suggest that the treatment of OTSCC with partial glossectomy followed by BRTx for positive/narrow margins and $+/-$ EBRTx to the neck $+/-$ CTx achieves outcomes comparable to traditional treatment algorithms. The use of BRTx removes the need for margin re-resection and complex re-reconstruction which may impact treatment package time and apply extra pressure on operative planning, as well as allows the avoidance of EBRTx to the oral cavity and morbidity associated with this. Margin control attained with post-resection BRTx in OTSCC may achieve a state where margins have no or limited impact on outcomes. Administration of BRTx in OTSCC is not difficult and allows acceptable and lower rates of complications than those previously reported with primary and adjuvant BRTx use in OTSCC.

As such, the use of intra-operative brachytherapy is a viable and interesting option to consider in a select population with oral tongue cancer. Our findings would serve as a stepping stone to a more robust multi-institutional trial with direct comparison to standard of practice.

\section{Abbreviations}

BRTx: Brachytherapy; CTx: Chemotherapy; CTV: Clinical Target Volume; DFS: Disease Free Survival; DSS: Disease Specific Survival; EBRTx: External Beam Radiation Therapy; ENE: Extranodal Extension; FoM: Floor of Mouth; HR: Hazard Ratio; IMRT: Intensity Modulated Radiotherapy; LA: Local Anaesthetic; LC: Local Control; LRC: Locoregional Control; LVS: Lymphovascular Spread; MDT: Multi-Disciplinary Team;

MTB: Multidisciplinary Tumour Board; ND: Neck Dissection; OAR: Organ at Risk; OCSCC: Oral Cavity Squamous Cell Carcinoma; ORN: Osteoradionecrosis; OS: Overall Survival; OTSCC: Oral Tongue Squamous Cell Carcinoma; PTV: Planning Target Volume; QoL: Quality of Life; RTOG: Radiation Therapy Oncology Group; WLE: Wide Local Excision

\section{Acknowledgements}

Not Applicable.

\section{Authors' contributions}

II: Data acquisition, analysis, interpretation; Manuscript drafting and revision. AM: Concept and design of study, Manuscript revision. MB: Concept and design of study. BB: Concept and design of study. KS: Concept and design of study, Data acquisition and analysis, Manuscript revision. MH: Concept and design of study, Data interpretation, Manuscript revision. All authors read and approved the final manuscript. 


\section{Availability of data and materials}

The data that support the findings of this study are available from the corresponding author upon reasonable request.

\section{Ethics approval and consent to participate}

Approved by "Research Ethics Committee of the CIUSSS West Central Montreal", reference number 07-119 CODIM-MBM-07-119.

\section{Consent for publication}

Not Applicable.

\section{Competing interests}

The authors declare that they have no competing interests.

\section{Author details}

'Department of Otolaryngology - Head \& Neck Surgery, Auckland District Health Board, Auckland City Hospital, Auckland, New Zealand. ${ }^{2}$ Department of Otolaryngology - Head \& Neck Surgery, Jewish General Hospital, McGill University, Montreal, Quebec, Canada. ${ }^{3}$ Department Radiation Oncology, Jewish General Hospital, McGill University, Montreal, Quebec, Canada.

Received: 3 June 2019 Accepted: 21 September 2020 Published online: 14 October 2020

\section{References}

1. Li R, Koch WM, Fakhry C, Gourin CG. Distinct epidemiologic characteristics of oral tongue cancer patients. Otolaryngol Head Neck Surg. 2013;148(5):792-6.

2. Moore SR, Johnson NW, Pierce AM, Wilson DF. The epidemiology of tongue cancer: a review of global incidence. Oral Dis. 2000;6(2):75-84.

3. Siegel RL, Miller KD, Jemal A. Cancer statistics, 2016. CA Cancer J Clin. 2016; 66(1):7-30.

4. Looser KG, Shah JP, Strong EW. The significance of "positive" margins in surgically resected epidermoid carcinomas. Head Neck Surg. 1978;1(2):107-11.

5. Sessions DG, Spector GJ, Lenox J, Haughey B, Chao C, Marks J. Analysis of treatment results for oral tongue cancer. Laryngoscope. 2002;112(4):616-25.

6. Byers RM, Bland KI, Borlase B, Luna M. The prognostic and therapeutic value of frozen section determinations in the surgical treatment of squamous carcinoma of the head and neck. Am J Surg. 1978;136(4):525-8.

7. Schwartz GJ, Mehta RH, Wenig BL, Shaligram C, Portugal LG. Salvage treatment for recurrent squamous cell carcinoma of the oral cavity. Head Neck. 2000;22(1):34-41.

8. Matoscevic K, Graf N, Pezier TF, Huber GF. Success of salvage treatment: a critical appraisal of salvage rates for different subsites of HNSCC. Otolaryngol Head Neck Surg. 2014;151(3):454-61.

9. Goineau A, Piot B, Malard O, Ferron C, Lisbona A, Cassagnau E, et al. Postoperative interstitial brachytherapy for resectable squamous cell carcinoma of the tonque. Brachytherapy. 2015;14(1):71-6.

10. Ayukawa F, Shibuya H, Yoshimura R, Watanabe H, Miura M. Curative brachytherapy for recurrent/residual tongue cancer. Strahlenther Onkol. 2007;183(3):133-7.

11. Stannard C, Maree G, Tovey S, Hunter A, Wetter J. Iodine-125 brachytherapy in the management of squamous cell carcinoma of the oral cavity and oropharynx. Brachytherapy. 2014;13(4):405-12.

12. Martinez-Monge R, Gomez-Iturriaga A, Cambeiro M, Garran C, Montesdeoca $\mathrm{N}$, Aristu JJ, et al. Phase I-II trial of perioperative high-dose-rate brachytherapy in oral cavity and oropharyngeal cancer. Brachytherapy. 2009; 8(1):26-33.

13. Petera J, Sirak I, Laco J, Kasaova L, Tucek L, Dolezalova H. High-dose-rate brachytherapy in early oral cancer with close or positive margins. Brachytherapy. 2015;14(1):77-83.

14. Bhalavat Rl, Mahantshetty UM, Tole S, Jamema SV. Treatment outcome with low-dose-rate interstitial brachytherapy in early-stage oral tongue cancers. J Cancer Res Ther. 2009;5(3):192-7.

15. Grégoire V, Ang K, Budach W, Grau C, Hamoir M, Langendijk JA, Lee A, Le QT, Maingon P, Nutting C, O'Sullivan B, Porceddu SV, Lengele B. Delineation of the neck node levels for head and neck tumors: a 2013 update. DAHA NCA, EORTC, HKNPCSG, NCIC CTG, NCRI, RTOG, TROG consensus guidelines. Radiother Oncol. 2014;110(1):172-81.

16. Lapeyre M, Bollet MA, Racadot S, Geoffrois L, Kaminsky MC, Hoffstetter $S$, et al. Postoperative brachytherapy alone and combined postoperative radiotherapy and brachytherapy boost for squamous cell carcinoma of the oral cavity, with positive or close margins. Head Neck. 2004;26(3):216-23.

17. Urashima Y, Nakamura K, Shioyama Y, Nomoto S, Ohga S, Toba T, et al. Treatment of early tongue carcinoma with brachytherapy: results over a 25year period. Anticancer Res. 2007;27(5b):3519-23.

18. Akiyama H, Yoshida K, Shimizutani K, Yamazaki H, Koizumi M, Yoshioka Y, et al. Dose reduction trial from $60 \mathrm{~Gy}$ in 10 fractions to $54 \mathrm{~Gy}$ in 9 fractions schedule in high-dose-rate interstitial brachytherapy for early oral tongue cancer. J Radiat Res. 2012;53(5):722-6.

19. Matsumoto K, Sasaki T, Shioyama Y, Nakamura K, Atsumi K, Nonoshita T, et al. Treatment outcome of high-dose-rate interstitial radiation therapy for patients with stage I and II mobile tongue cancer. Jpn J Clin Oncol. 2013; 43(10):1012-7.

20. Bansal A, Ghoshal S, Oinam AS, Sharma SC, Dhanireddy B, Kapoor R. Highdose-rate interstitial brachytherapy in early stage oral tongue cancer - 15 year experience from a tertiary care institute. J Contemp Brachytherapy. 2016;8(1):56-65.

21. Ling W, Mijiti A, Moming A. Survival pattern and prognostic factors of patients with squamous cell carcinoma of the tonque: a retrospective analysis of 210 cases. J Oral Maxillofac Surg. 2013;71(4):775-85.

22. Okuyemi OT, Piccirillo JF, Spitznagel E. TNM staging compared with a new clinicopathological model in predicting oral tongue squamous cell carcinoma survival. Head Neck. 2014;36(10):1481-9.

23. Mroueh R, Haapaniemi A, Grenman R, Laranne J, Pukkila M, Almangush A, et al. Improved outcomes with oral tongue squamous cell carcinoma in Finland. Head Neck. 2017:39(7):1306-12.

24. Liao CT, Wen YW, Yang LY, Lee SR, Ng SH, Liu TW, et al. Comparative clinical outcomes of Taiwanese patients with resected buccal and tongue squamous cell carcinomas. Oral Oncol. 2017;67:95-102.

25. Zhang YY, Wang DC, Su JZ, Jia LF, Peng X, Yu GY. Clinicopathological characteristics and outcomes of squamous cell carcinoma of the tongue in different age groups. Head Neck. 2017;39:2276-82.

26. Zanoni DK, Migliacci JC, Xu B, Katabi N, Montero PH, Ganly I, et al. A proposal to redefine close surgical margins in squamous cell carcinoma of the Oral tongue. JAMA Otolaryngol Head Neck Surg. 2017:143(6):555-60

27. Chen MM, Harris JP, Orosco RK, Sirjani D, Hara W, Divi V. Association of Time between surgery and adjuvant therapy with survival in Oral cavity Cancer. Otolaryngol-Head Neck Surg. 2018;158:1051-6.

28. Mistry RC, Qureshi SS, Kumaran C. Post-resection mucosal margin shrinkage in oral cancer: quantification and significance. J Surg Oncol. 2005;91(2):131-3.

29. Umstattd LA, Mills JC, Critchlow WA, Renner GJ, Zitsch RP. 3rd. Shrinkage in oral squamous cell carcinoma: an analysis of tumor and margin measurements in vivo, post-resection, and post-formalin fixation. Am J Otolaryngol. 2017;38(6):660-2.

\section{Publisher's Note}

Springer Nature remains neutral with regard to jurisdictional claims in published maps and institutional affiliations.

Ready to submit your research? Choose BMC and benefit from:

- fast, convenient online submission

- thorough peer review by experienced researchers in your field

- rapid publication on acceptance

- support for research data, including large and complex data types

- gold Open Access which fosters wider collaboration and increased citations

- maximum visibility for your research: over $100 \mathrm{M}$ website views per year

At $\mathrm{BMC}$, research is always in progress.

Learn more biomedcentral.com/submissions 